\title{
Resources Construction on English Mobile Learning in Big data Era
}

\author{
Xiuli Qu \\ Teaching and Research Institute of Foreign Languages, Bohai University, Jinzhou, 121013, China \\ lename2008@126.com
}

Keywords: big data era; English mobile learning; resources construction; foreign language teaching

\begin{abstract}
Big data is the informationization and Internet information revolution after another peak, education big data is the data in the service of education and guide the benign development of the education system of technology and application, large data combined with mobile learning to open new avenues of learning foreign language. Mobile learning resources construction is the important basis of mobile learning, this paper studies the large data era of English mobile learning resources construction of the key issues, including big data model, based on large data of foreign language learning English mobile learning resources system, based on large data English of English mobile learning resources construction process of English. In this paper, the application of research results, for deepening the reform of English teaching, improve the quality of English teaching and cultivate the students' application ability, etc, will play an important role.
\end{abstract}

\section{Introduction}

Big data is considered to be the informationization and the Internet the information revolution after another peak. Big data is about to bring a subversive revolution, and will promote the social comprehensive progress production. Big data is a network technology, artificial intelligence and the effective combination of database technology and other modern information technology, is an effective way to solve data rich and poor knowledge. Big data is not only a state of vast amounts of data and its corresponding data processing technique, but also a way of thinking and an important infrastructure."Big" of big data, not only refers to the large capacity, more is through the huge amounts of data exchange, integration and analysis, found the new knowledge, to create new value, a "great knowledge", "big science and technology", "big profits" and "great development". Education big data refers to data in the service of education and guide the benign development of the education teaching technology and application of the system. The rapid development of network makes the school has the enormous data available, high quality gradually become a reality, big data also play a major role in the education application. Education big data will be collected together before see, less than, and do not take the data, and will promote the transformation education teaching in the following aspects: the education process from "quantitative" to "quantitative", education decision from the "experience" to the "scientific", education mode from the "popularity" to "personalized," education management from "invisible" to "visualization".

Mobile learning is a kind of can occur at any time, any place in the study, mainly depends on the mature wireless communication technology, wireless mobile networks, new electronic technology such as electronic information technology, its main characteristic is its mobility, the traditional teaching model requires students to study in the classroom, and mobile learning model can learn English anytime and anywhere, without being limited by the objective environment, mobile learning the use of mobile computing devices can effectively provide two-way interactive communication between teachers and learners, without being limited by the traditional English teaching model of space and time, improve students' learning of personalized and autonomy, a learning model is indispensable to the future, lifelong learning and interdisciplinary education for people opened up a new way. English is one of the most common language in the world, learning English well helps to exchange and cooperation with the people of the world. Since China's accession to the WTO, every field constantly with the world, the future requirements for talents of foreign language ability is higher and higher."College English curriculum requirements", points out 
that the institutions of higher learning should make full use of modern information technology, based on the computer and the classroom English teaching mode, the improvement is given priority to with teachers' teaching of the single teaching mode. New teaching model should be to modern information technology, especially network technology as the support, can make the teaching and learning of English in a certain extent, not limited by time and place, the direction of individualized and autonomous learning. To carry out mobile learning in college English teaching in order to establish student-centered, self control learning progress, personalized learning way to explore a new way.

Big data combined with mobile learning to open new avenues of learning foreign language. Foreign language learning resources have a lot of typical characteristics of the learning resources, mobile learning resources construction is the foundation of mobile learning. English mobile learning resources construction is the guarantee of mobile learning effectiveness and an important foundation for learning, this paper studies the English mobile learning resources construction of the large data era, for deepening the reform of English teaching, improve the level of English teaching services.

\section{Foreign Language Learning Model based on Big Data}

Big data is applied to mobile learning, through to the learners to produce huge amounts of data processing and analysis, so as to realize the learners personalized guidance, make learners learn the road of healthy development. Data throughout the entire learning activities, teachers through massive amounts of data analysis of students, grasp every students personalized features, and for each student to provide adaptive learning resources, make the use of adaptive learning resources on autonomous learning, the difficulties encountered in the learning process of online instruction by teachers, so as to ensure that students successfully complete the study task. The whole learning process, data on students' learning plays a guiding and monitoring role, student's learning process is recorded in real time, for the next round of learning will provide rich data support, eventually make the study on the development path of a virtuous cycle. Under the background of big data model of foreign language learning consists of two guide inner loop and outer loop, to quantify and wisdom of foreign language teaching innovation provide clear conceptual framework and cognitive premise model structure is shown in Fig. 1.

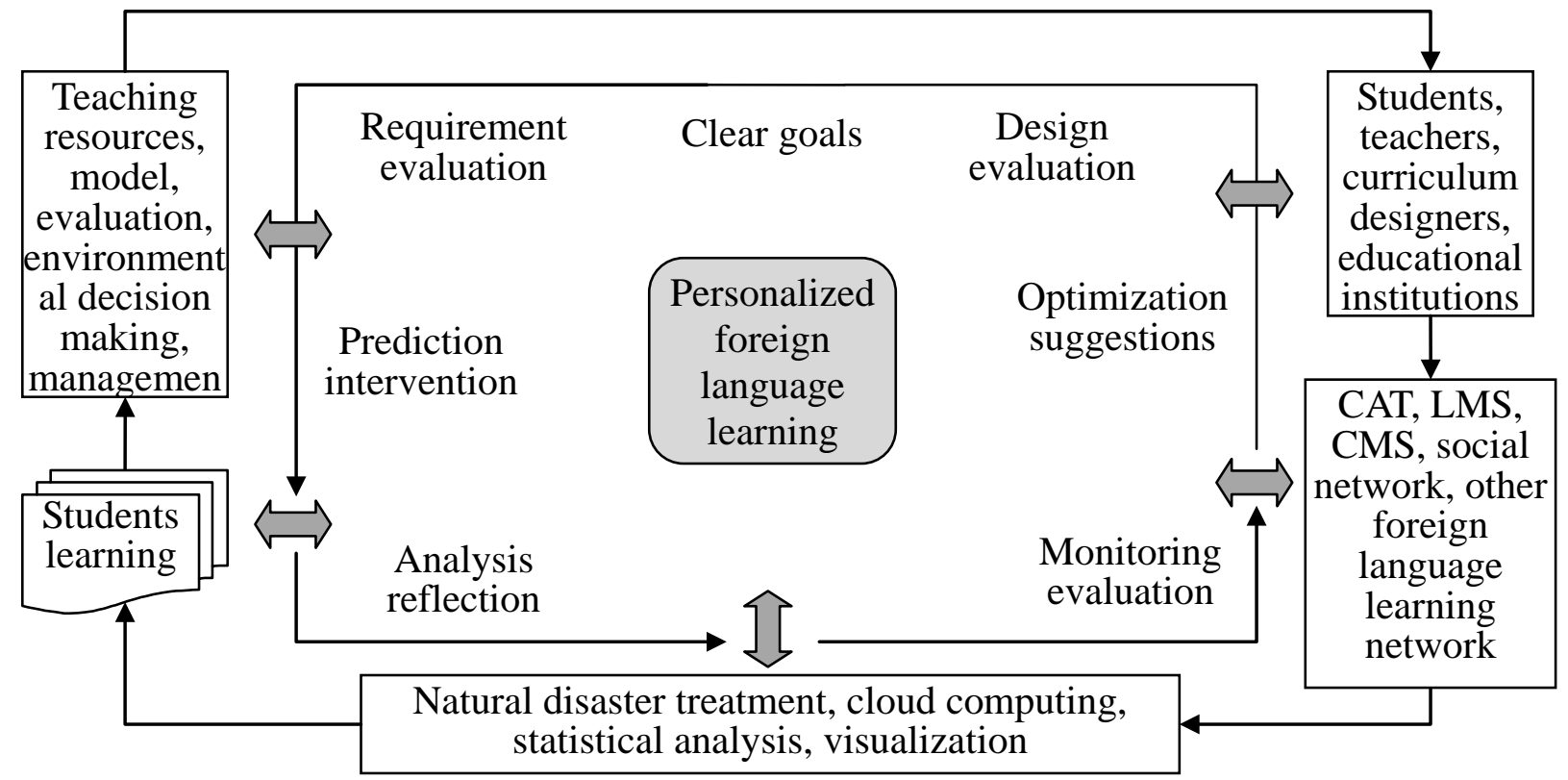

Fig. 1. Foreign language learning model based on big data

Inner loop is also called the guiding layer, by clear objectives, assessment requirements, design, assessment, optimization proposal, monitoring, evaluation, analysis, reflection and monitor intervention, etc; Outer loop also calls the operational layer, inner loop circulation influence abroad. 
External loop to student learning as the starting point, the teaching management, stakeholders, data source and the information technology and so on four parts. Inner loop and outer loop interactions, jointly promote mobile learning.

\section{Composition on English Mobile Learning Resources System based on Big Data}

Construction of teaching resources can have four levels of meanings, one is the material construction of teaching resources, divided into four categories, respectively is question bank, stock image, course base and putted forward; Secondly, the construction of network course library; Three is the development of education resource management system; Four is the development of universal mobile learning system support platform. In the four levels, network curriculum and class teaching resource construction is the key and core materials, the construction of the third and fourth level is the tool level, the specific content of network courses and material resources, the formation of many different characteristics, the corresponding management system and teaching system must adapt to this kind of change English mobile learning resources based on large data system consists of three levels, respectively is the user layer, function layer and data layer, as shown in Fig. 1.

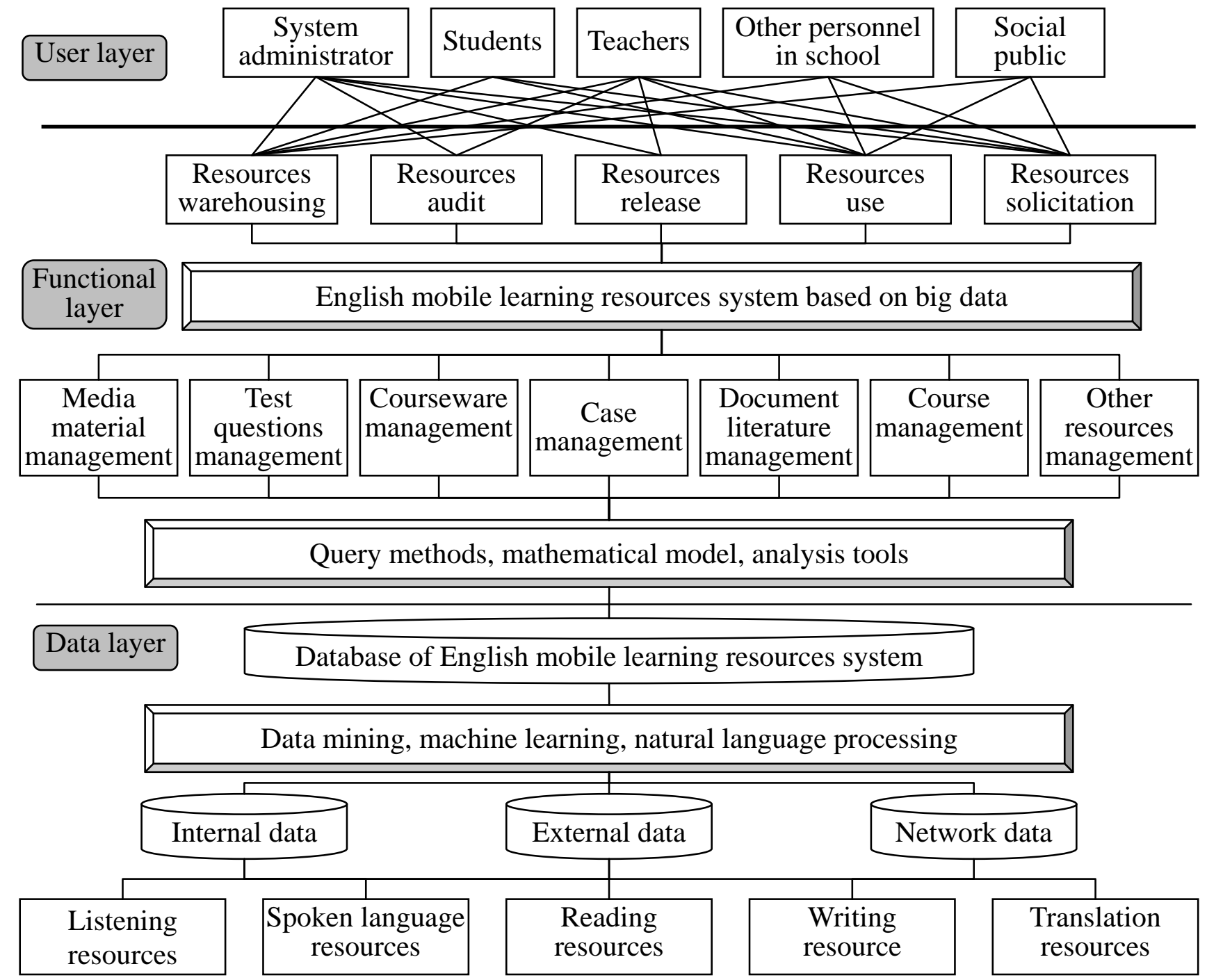

Fig. 2. Composition on English mobile learning resources system based on big data

(1) User layer. Including system administrators, students, teachers, school personnel and other five categories such as public users. The system administrator, with full authority, responsible for system operation and maintenance; Students, is the direct object of service of learning resources, the use of learning resources for learning, can also be made to gather resources into the Treasury; Teachers to guide students to learn, but also has the storage of resources, audit, resources 
distribution and resources collection and other rights; Other researchers, including the department in charge of the department in charge of teaching staff, students and logistics departments; The social public, can through access to learning resources, but access is small, can only access to part of the open resource.

(2) Function layer. Provide system use related functions, including operation and resource management functions, etc. Operating functions for the use of system of various kinds of users directly, core functions including resource library, audit resources, resources distribution, resource use and resource collection, non-core functions including system maintenance, data maintenance, operation management and resources exchange, etc.; Resource management function is used to manage all kinds of resources, including material management, test question management, media courseware management, case management, document management, course management, and other resource management, etc.

(3) Data layer. English teaching goal is to develop the students' ability of cross-cultural communication, mainly in "listening, speaking, reading, writing and translation" and the cultivation of ability. Efforts to create the language environment of "hear", strengthen the training function of "said", train the ability of "read" the accurate, the cultivation of the "write" material ability of organization transformation ability of "translation". Therefore, English mobile learning resources including English listening, speaking, reading, writing and translation resources. These resources from the school, school internal external and the Internet. To these resources through data mining, machine learning and natural language processing, forming English mobile learning resources database system, for the use of mobile learning.

\section{Construction Process on English Mobile Learning Resources based on Big Data}

According to the waterfall model of software engineering, combining the characteristics of mobile learning resources construction, based on large data of English mobile learning resources construction process is shown in Fig. 3.Which includes five steps: analysis of mobile learning resources construction, mainly for technical analysis, fully consider all technical issues on resources construction, as far as possible using mature technology, introducing advanced technology carefully. And other aspects of analysis, including learning goal, learners and the curriculum nature analysis, etc.; Mobile learning resources design, the design content to be able to continue to inspire and sustain learners' learning motivation and interest. Media design text design, graphic design, audio, video, animation design, interaction design including learning content is relatively simple text messaging, and rich learning content browsing form; Mobile learning resources development tool selection. The current mobile learning resources development includes the following three types of platform and tools, to make choice according to the actual situation before the development; Mobile learning resources development for learners to create meaningful learning situation, and provide learning strategies for learners' problems in real situation. Also can provide learners with the expanding of rich learning resources and help learners to solve practical problems. Mobile learning resources test and evaluation.

\section{Conclusion}

With the emergence and rapid development of mobile technology, mobile devices are increasingly perfect function, provide English teaching with the diversification of a situation, the space-time fan in the new teaching environment, operation convenient and personalized learning, the characteristics of mobile technology and English teaching itself has made the integration of both has a natural connection and good foundation, based on large data of mobile learning is a auxiliary method in the teaching of English, to break the traditional English teaching mode of boundaries of time and space, expanded the English classroom teaching, to formal learning and informal learning outside class effective connectivity, created the perfect English learning environment, to make up for the limitations of classroom teaching, to improve the students' learning enthusiasm. Based on the research achievements in this paper, to solve the big data era the key issues of English mobile 
learning resources construction, and provide reference for other subjects of mobile learning resources construction.

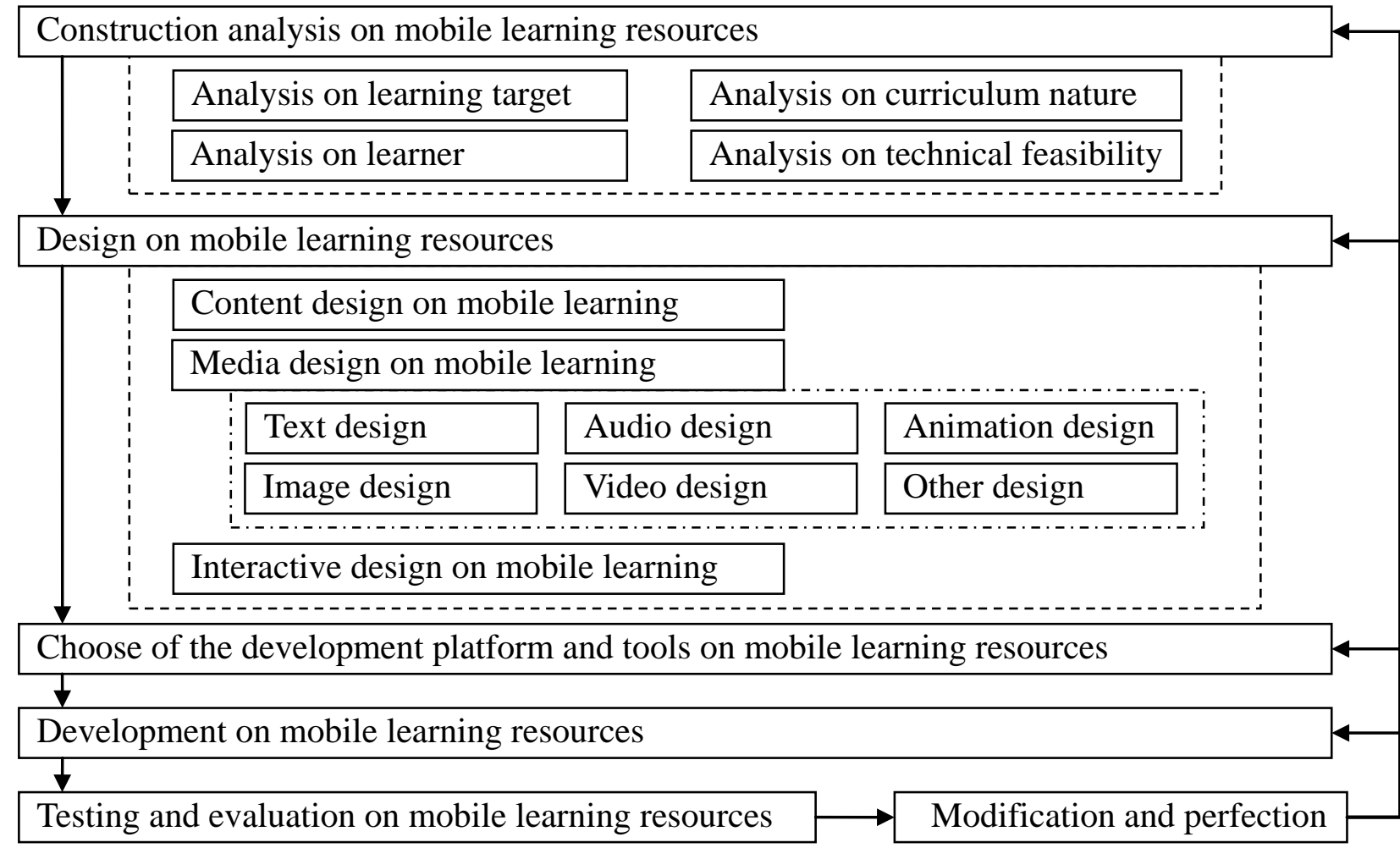

Fig. 3. Construction process on English mobile learning resources system based on big data

\section{References}

[1] Jason J. Jung, "Computational Collective Intelligence with Big Data: Challenges and Opportunities," Future Generation Computer Systems, vol. 65, no. 1, pp. 87-88, 2016.

[2] Z. J. Xu, Y. Fu, "Information exploration of scientific research management in Universities under the environment of large data," Technology and innovation management, vol. 35, no. 2, pp. 112-115, 2014.

[3] Baidu Knows, "The impact of big data on future education," https://zhidao.baidu.com/question/458696862669645565.html, 2016-11-5.

[4] Phoenix information, "Big data driven education reform," http://news.ifeng.com/a/20161112/50246798_0.shtml, 2016-11-5.

[5] W. R. Yang, "Research on the innovation of university scientific research management in the era of big data," Scientific management research, vol. 35, no. 14, pp. 1-4, 2015.

[6] Y. C. Wang, "Analysis of the application of big data in mobile learning," China Information Technology Education, vol. 17, no. Z3, pp. 169-172, 2016.

[7] Z. J. Yu, "Technology analysis of mobile learning resource development," Journal of ABC Wuhan Management Institute, vol. 23, no. 6, pp. 61-63, 2013.

[8] H. M. Jia, "A study on the construction of College English mobile learning resources based on the theory of Situated Cognition," Journal of Chifeng University (Philosophy and Social Science Chinese Edition), vol. 36, no. 10, pp. 270-271, 2015.

[9] Y. B. Lu, P. Zhi, "Research on foreign language teaching mode based on mobile learning terminal," Modern educational technology, vol. 23, no. 6, pp. 71-75, 2013. 